\title{
Bobath and traditional approaches in post-stroke gait rehabilitation in adults
}

\author{
Emilia Mikołajewska ${ }^{1,2}$ \\ ${ }^{1}$ Department of Physiotherapy, Faculty of Health Sciences, Ludwik Rydygier Collegium Medicum in Bydgoszcz, Nicolaus \\ Copernicus University in Toruń, Poland; ${ }^{2}$ Neurocognitive Laboratory, Centre for Modern Interdysciplinary Technologies, \\ Nicolaus Copernicus University in Toruń, Poland
}

\section{Summary}

Study aim: The aim of this study was to compare the outcomes of a study of post-stroke gait reeducation using the Bobath neuro-developmental treatment (NDT-Bobath) method and the traditional approach.

Material and methods: The study included 30 adult patients after ischemic stroke, aged 32-82. Patients were randomly assigned to one of the treatment groups: the study group (treated with the NDT-Bobath method combined with the traditional approach, ten sessions), and a reference group (treated with the traditional method only, ten sessions). The measurements (spatio-temporal gait parameters based on $10 \mathrm{~m}$ walking test: gait velocity, normalized gait velocity, cadence, normalized cadence, stride length, and normalized stride length) were administered twice: on admission (before the therapy) and after the last therapy session.

Results: Statistically significant and favorable changes in the gait velocity, cadence and stride length regarding their normalized values were observed. Moderate and high correlations among changes of assessed spatio-temporal gait parameters were observed in both groups.

Conclusions: The NDT-Bobath method may be regarded as a more effective form of gait post-stroke rehabilitation in young adults compared to traditional rehabilitation.

Keywords: Rehabilitation - Stroke - Gait re-education - Gait analysis - Normalized parameters of gait - NDT-Bobath

\section{Introduction}

Despite stroke incidence and mortality rates slowly decreasing in selected countries (especially developed Western Europe countries) [6,7], stroke is still regarded as one of the leading causes of death and long-term disability. Ischemic stroke cases constitute approximately 70-80\% of all stroke cases $[6,7]$. Post-stroke gait disorder reduces mobility of patients, their independence, participation in activities of daily living and community life. Gait disorders may be reflected in spatio-temporal gait parameters. Their assessment may be a useful basic or supplementary way to assess general efficiency of gait function restoration during a neurorehabilitation program.

The Bobath neuro-developmental treatment (NDTBobath) method for adults is still one of the most popular therapeutic methods in neurorehabilitation, including gait relearning [8, 21]. Current studies concerning its use in post-stroke gait relearning have methodological concerns related to study/treatment fidelity and measurement [16]. For this moment there is insufficient evidence (especially from randomized controlled trials - RCTs) to conclude that a particular physiotherapy method (including NDT-Bobath) is more effective in promoting recovery of gait than any other approach. Moreover, combined use of NDT-Bobath and components of any other approaches may diminish the aforementioned picture. The assumption that rehabilitation using a proper mix of components derived from different approaches may be more effective than no treatment control in attaining gait function following stroke may be true [18]. Research on various mixed/eclectic approaches constitute an important step toward patient-tailored therapy and the need for further support. Current evidence concerning combined use of the NDT-Bobath method and components of another

Author's address Emilia Mikołajewska, Department of Physiotherapy, Faculty of Health Sciences, Ludwik Rydygier Collegium Medicum in Bydgoszcz, Nicolaus Copernicus University in Toruń, Jagiellońska 13-15, 85-067 Bydgoszcz, Poland e.mikolajewska@wp.pl; emiliam@cm.umk.pl 
therapeutic approach is weak. Evidence of favorable combined use of the NDT-Bobath method is as follows:

- successful use of mixed rehabilitative procedures, including NDT-Bobath, in an individual training package [17],

- therapy based on the NDT-Bobath concept supported by task practice is more effective than task practice alone [9],

- injection of botulinum toxin type A combined with NDT-Bobath therapy showed improvements in lower limb spasticity, gait and balance in post-stroke patients greater than use of botulinum toxin type A alone [11].

The aim of this study was compare the outcomes of a study ofpost-stroke gait rehabilitation using the NDTBobath method for adults combined with the traditional approach and the sole traditional approach.

\section{Material and methods}

The study design was pre test/post test control.

\section{Material}

The research was conducted among 30 adult patients after ischemic stroke. Patients were randomly assigned to one of the following treatment groups:

- study group (treated with NDT-Bobath method combined with traditional approach, $\mathrm{n}=15$ ),
- reference group (treated with traditional method only, $\mathrm{n}=15)$.

The patients' flow diagram is presented in Figure 1.

Inclusion criteria were:

- age above 18 years old,

- diagnosis: ischemic stroke,

- time after ischemic stroke from four weeks to three years,

- lack of contraindications to rehabilitation,

- ability to walk.

Exclusion criteria were:

- age below 18 years old,

- diagnosis: hemorrhagic stroke or transient ischemic attack (TIA),

- time after ischemic stroke below four weeks or above three years,

- contraindications to rehabilitation, and lack of ability to walk.

A summary of the patients' overall profile is presented in Table 1.

This study was conducted in accordance with the Declaration of Helsinki and the guidelines for Good Clinical Practice (GCP). Written informed consent was obtained from every patient prior to this study.

\section{Methods}

The ten-meter walking test (10MWT) was used to assess main spatio-temporal gait parameters: gait velocity,

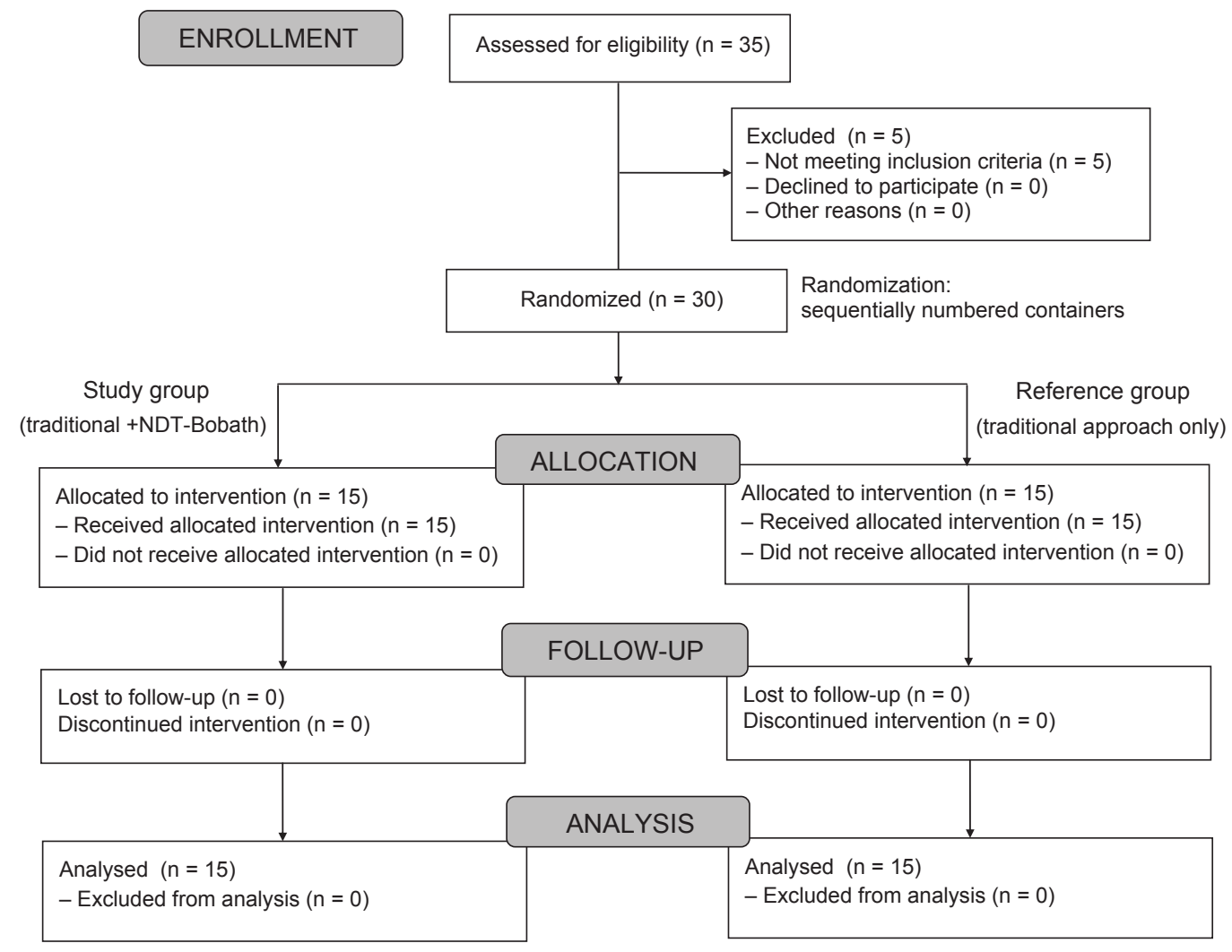

Fig. 1. Patient's flow diagram 
Table 1. Patients' overall profile

\begin{tabular}{|c|c|c|}
\hline Parameter & $\begin{array}{c}\text { Study group } \\
\mathrm{n}=15(100 \%)\end{array}$ & $\begin{array}{c}\text { Reference group } \\
\mathrm{n}=15(100 \%)\end{array}$ \\
\hline \multicolumn{3}{|l|}{ Age [years]: } \\
\hline mean & 54.85 & 52.5 \\
\hline SD & 12.77 & 13.29 \\
\hline $\min$ & 32 & 36 \\
\hline Q1 & 46 & 48 \\
\hline median (Q2) & 54.5 & 56.5 \\
\hline Q3 & 65 & 66.5 \\
\hline $\max$ & 77 & 82 \\
\hline \multicolumn{3}{|c|}{ ASIS to the medial malleolus distance $[\mathrm{m}]$ : } \\
\hline mean & 0.8 & 0.8 \\
\hline SD & 0.05 & 0.06 \\
\hline $\min$ & 0.72 & 0.71 \\
\hline Q1 & 0.76 & 0.75 \\
\hline median $(\mathrm{Q} 2)$ & 0.78 & 0.79 \\
\hline Q3 & 0.84 & 0.83 \\
\hline $\max$ & 0.91 & 0.87 \\
\hline \multicolumn{3}{|l|}{ Height $[\mathrm{m}]$ : } \\
\hline mean & 1.71 & 1.7 \\
\hline SD & 0.06 & 0.05 \\
\hline $\min$ & 1.55 & 1.58 \\
\hline Q1 & 1.66 & 1.64 \\
\hline median (Q2) & 1.71 & 0.7 \\
\hline Q3 & 1.75 & 1.74 \\
\hline $\max$ & 1.83 & 1.79 \\
\hline \multicolumn{3}{|l|}{ Gender: } \\
\hline $\mathrm{F}$ & $7(46.67 \%)$ & $6(40 \%)$ \\
\hline M & $8(53.33 \%)$ & $9(60 \%)$ \\
\hline \multicolumn{3}{|c|}{ Side of paresis: } \\
\hline $\mathrm{L}$ & $8(53.33 \%)$ & $7(46.67 \%)$ \\
\hline $\mathrm{R}$ & $7(46.67 \%)$ & $8(53.33 \%)$ \\
\hline \multicolumn{3}{|c|}{ Time after CVA [weeks]: } \\
\hline SD & 13.47 & 16.02 \\
\hline $\min$ & 5 & 7 \\
\hline Q1 & 29 & 31 \\
\hline median (Q2) & 59 & 61 \\
\hline Q3 & 103 & 109 \\
\hline $\max$ & 153 & 155 \\
\hline
\end{tabular}

normalized gait velocity, cadence, normalized cadence, stride length, and normalized stride length. The test was recorded using a digital video camera and analyzed both in real time (where available) and post-hoc to achieve validity and reliability of assessment.

Use of normalized values may strengthen evidence of the compartmental study. Anterior superior iliac spine (ASIS) to the medial malleolus distance (leg length) was measured in each patient and was used to calculate normalized values.
Methodological concerns related to fidelity and measurement within studies incorporating the NDT-Bobath method mentioned by Vaughan-Graham et al. [21] and Paci [16] have been improved thanks to the following solutions:

- measurements (with recording) were performed in every patient twice: on admission (before the therapy) and after the last session of the therapy,

- each patient underwent the same number of therapeutic sessions (ten) through two weeks (ten days of the therapy), 
- all measurements were administered by the same scientist,

- all patients completed the measures in the same conditions,

- therapy was conducted by the same physical therapist with more than fifteen years of experience in neurorehabilitation, and NDT-Bobath skills confirmed by basic and advanced courses in NDT-Bobath for adults, and additionally, to broaden knowledge and experience in the NDT-Bobath approach, by NDT-Bobath for children and NDT-Bobath Baby courses.

There is an assumption that rehabilitation effects have been reflected by changes of assessed parameters. Such detailed description of the study is important for replication purposes, compartmental studies or further development of the proposed methodology [16].

\section{Statistical analysis}

All data were collected and stored using the MS Excel 2013 software. The Shapiro-Wilk test was used to assess normality of the data distribution. Mean, standard deviation (SD), minimum value (min), Q1, median (Q2), Q3, and maximum value (max) were calculated where possible to show the results of this study. To assess the dynamics of changes within and between groups ANOVA and post-hoc tests (to provide further details after an analysis of variance) were used to compare scores. Change of parameters before/after therapy was calculated as a result of subtraction. Spearman's rho was used to assess correlations among changes of parameters.

Statistical analysis was performed using IBM SPSS Statistics 23.

The level of significance of $\mathrm{p}<0.05$ was assumed.

\section{Results}

The results are presented in Tables 2-4.

Mixed ANOVA was used, with number of measure (I: on admission, II: at discharge) as the within-subjects factor, and treatment (study group, reference group) as the between-subjects factor.

Statistically significant and favorable changes in the gait velocity, cadence and stride length and their normalized values were observed in both groups (within groups and between groups). Aforementioned changes were higher in the study group; thus NDT-Bobath combined with the traditional approach may be perceived as more effective than the traditional approach alone.

Moderate and high correlations among changes of assessed spatio-temporal gait parameters were observed. There was observed no statistically significant correlation between cadence and stride length and normalized stride length; thus we may regard aforementioned parameters independent in the study group.

Table 2. Statistically significant changes of parameters in both groups

\begin{tabular}{|c|c|c|c|c|c|c|c|}
\hline \multirow[b]{2}{*}{ Value } & & \multicolumn{6}{|c|}{ Parameter } \\
\hline & & $\begin{array}{c}\text { Gait } \\
\text { velocity }\end{array}$ & Cadence & $\begin{array}{l}\text { Stride } \\
\text { length }\end{array}$ & $\begin{array}{l}\text { Normalized } \\
\text { gait velocity }\end{array}$ & $\begin{array}{c}\text { Normalized } \\
\text { cadence }\end{array}$ & $\begin{array}{l}\text { Normalized } \\
\text { stride length }\end{array}$ \\
\hline \multirow{7}{*}{$\begin{array}{l}\text { Changes } \\
\text { in study } \\
\text { group }\end{array}$} & Mean & 0.35 & 17.75 & 0.39 & 0.11 & 0.09 & 0.54 \\
\hline & $\mathrm{SD}$ & 0.08 & 4.12 & 0.11 & 0.04 & 0.02 & 0.17 \\
\hline & Min & 0.03 & 5 & 0.11 & 0.02 & 0.02 & 0.14 \\
\hline & Q1 & 0.19 & 10.75 & 0.25 & 0.07 & 0.05 & 0.34 \\
\hline & Median & 0.42 & 19 & 0.4 & 0.11 & 0.08 & 0.55 \\
\hline & Q3 & 0.57 & 39 & 0.72 & 0.16 & 0.17 & 0.78 \\
\hline & Max & 0.71 & 62 & 1.22 & 0.24 & 0.32 & 1.09 \\
\hline \multirow{7}{*}{$\begin{array}{l}\text { Changes } \\
\text { in reference } \\
\text { group }\end{array}$} & Mean & 0.17 & 12.24 & 0.23 & 0.05 & 0.06 & 0.2 \\
\hline & $\mathrm{SD}$ & 0.04 & 3.21 & 0.06 & 0.02 & 0.02 & 0.06 \\
\hline & Min & 0.01 & 2 & 0.05 & 0.02 & 0.01 & 0.05 \\
\hline & Q1 & 0.07 & 6.5 & 0.13 & 0.03 & 0.03 & 0.11 \\
\hline & Median & 0.15 & 12.5 & 0.2 & 0.05 & 0.06 & 0.17 \\
\hline & Q3 & 0.32 & 26.5 & 0.31 & 0.13 & 0.16 & 0.27 \\
\hline & Max & 0.63 & 51 & 0.57 & 0.22 & 0.29 & 0.49 \\
\hline
\end{tabular}


Table 3. Correlations of changes in study group

\begin{tabular}{lccccc}
\hline & Cadence & Stride length & Normalized gait velocity & Normalized cadence & Normalized stride length \\
\hline Gait velocity & 0.599 & 0.676 & 0.729 & 0.589 & 0.629 \\
& $\mathrm{p}=0.012$ & $\mathrm{p}=0.029$ & $\mathrm{p}=0.016$ & $\mathrm{p}=0.017$ & $\mathrm{p}=0.014$ \\
Cadence & - & n.s. & 0.669 & 0.779 & $\mathrm{p}=0.017$ \\
& & $\mathrm{p}=0.011$ & 0.556 & $\mathrm{p}=0.022$ & $\mathrm{p}=0.013$ \\
Stride length & & - & 0.712 & 0.699 & 0.657 \\
Normalized & & & $\mathrm{p}=0.004$ & $\mathrm{p}=0.037$ & 0.014 \\
gait velocity & & & & - & 0.588 \\
$\begin{array}{l}\text { Normalized } \\
\text { cadence }\end{array}$ & & & & $\mathrm{p}=0.034$ \\
\hline
\end{tabular}

n.s. - not significant.

Table. 4. Correlations of changes in reference group

\begin{tabular}{lccccc}
\hline & Cadence & Stride length & Normalized gait velocity & Normalized cadence & Normalized stride length \\
\hline \multirow{2}{*}{ Gait velocity } & 0.512 & 0.578 & 0.728 & 0.613 & 0.498 \\
& $\mathrm{p}=0.021$ & $\mathrm{p}=0.014$ & $\mathrm{p}=0.022$ & $\mathrm{p}=0.011$ & $\mathrm{p}=0.029$ \\
Cadence & - & n.s. & 0.522 & 0.701 & n.s. \\
& & & $\mathrm{p}=0.012$ & $\mathrm{p}=0.011$ & 0.712 \\
Stride length & & - & $\mathrm{p}=0.027$ & $\mathrm{p}=0.488$ & $\mathrm{p}=0.044$ \\
Normalized & & - & 0.611 & 0.411 \\
$\begin{array}{l}\text { gait velocity } \\
\text { Normalized }\end{array}$ & & & $\mathrm{p}=0.012$ & $\mathrm{p}=0.012$ \\
cadence & & & - & n.s. \\
\hline
\end{tabular}

n.s. - not significant.

Moderate and high correlations among changes of assessed spatio-temporal gait parameters were observed. There was observed no statistically significant correlation between cadence and stride length and normalized stride length and normalized cadence and normalized stride length, comparing between normalized cadence and normalized stride length; thus we may consider the aforementioned parameters independent in the study group.

Correlations within the ref-erence group were significantly lower than respectivecorrelations in the study group.

\section{Discussion}

Although numerous problems relating to proper gait relearning in adult post-stroke patients have been explained, there is still no prevailing neurorehabilitation approach. Outcomes of RCT-based compartmental studies in post-stroke gait rehabilitation of adult patients require further research and in-depth analysis.

Greater changes before/after therapy in all measured parameters were observed in the study group. This strengthens the evidence that NDT-Bobath combined with a traditional approach is more effective than a traditional approach alone in post-stroke gait rehabilitation. However, we consider this a pilot study due to the following limitations:

- limited sample of patients $(n=30)$,

- only immediate results of the rehabilitation were assessed.

On the other hand, the proposed methodology may help eliminate sources of potential bias or imprecision mentioned by other scientists and clinicians. Generalization and applicability of the study findings cause that the presented outcomes may be applied in the clinic right away, strengthening the position of the NDT-Bobath method in gait neurorehabilitation in post-stroke adults. 
Thus it seems that the benefits and limitations of the study are balanced.

A further randomized study is planned to assess changes of the assessed parameters in three groups (traditional, NDT-Bobath, combined) in a bigger sample, with assessment of the long-term rehabilitation-related changes. There is also a need for in-depth analysis of predictors of recovery such as functional status (outcomes of clinimetric tests) on admission, age, gender, time after CVA, side of paresis, body mass index (BMI), etc. Also helpful may be improved novel methodology including semi-automatic gathering of parameters from digital files and assessing additional parameters, e.g. asymmetry patterns [13].

Compartmental BAS studies concerning the NDT-Bobath for adults method in gait rehabilitation are rare. The study by Kılınç et al. (2016) provided evidence that NDTBobath-based rehabilitation improved walking ability in post-stroke patients more than traditional therapy [5]. The limited evidence (due to lack of a reference group) of efficiency of the NDT-Bobath method in gait reeducation in adult post-stroke patients was described previously in several studies $[1,5,10,12-15,19]$. Results described in this article are similar to the aforementioned, but constitute stronger evidence. Gait ability is influenced by standing balance and trunk balance [19]. The NDT-Bobath method proved to improve the balance of the body better than the proprioceptive neuromuscular facilitation (PNF) method; moreover, its efficiency did not depend on hand paresis [3]. Further evidence concerning improvement in walking long distances on different surfaces and around obstacles after 3 weeks of NDT-Bobath rehabilitation in post-stroke patients was provided by Benito Garcia et al. [1]. On the other hand, the motor relearning program (MRP) was more effective than the NDT-Bobath approach in acute rehabilitation of patients with stroke [2]. Improvement of gait ability in the group of patients with post-stroke hemiparesis treated with the NDT-Bobath method was assessed as similar to outcomes of robot-based therapy [4].

No important harm or unintended effects were observed.

\section{Conclusions}

NDT-Bobath combined with the traditional approach may be regarded as more effective than the traditional approach alone in post-stroke gait rehabilitation. More statistically significant and favorable changes in the gait velocity, cadence and stride length regarding their normalized values were observed in the group treated with the NDT-Bobath combined with the traditional approach. Moderate and high correlations among changes of assessed spatio-temporal gait parameters were observed in both groups, but they were higher in the group treated with NDT-Bobath combined with the traditional approach.

Recommendation: There is a need for further research developing the methodology presented in the described pilot study.

\section{Conflict of interest: Authors state no conflict of interest.}

\section{References}

1. Benito García M., Atín Arratibel M.Á., Terradillos Azpiroz M.E. (2015) The Bobath Concept in walking activity in chronic Stroke measured through the International Classification of Functioning, Disability and Health. Physiother. Res. Int., 20(4): 242-250.

2. Brock K., Haase G., Rothacher G., Cotton S. (2011) Does physiotherapy based on the Bobath concept, in conjunction with a task practice, achieve greater improvement in walking ability in people with stroke compared to physiotherapy focused on structured task practice alone?: a pilot randomized controlled trial. Clin. Rehabil., 25(10): 903-912.

3. Chen J.C., Shaw F.Z. (2014) Progress in sensorimotor rehabilitative physical therapy programs for stroke patients. World J. Clin. Cases., 2(8): 316-326.

4. Gallagher S., Phadke C.P., Ismail F., Boulias C. (2015) Physical therapy for an adult with chronic stroke after botulinum toxin injection for spasticity: a case report. Physiother. Can., 67(1): 65-68.

5. Kılınç M., Avcu F., Onursal O., Ayvat E., Savcun Demirci C., Aksu Yildirim S. (2016) The effects of Bobathbased trunk exercises on trunk control, functional capacity, balance, and gait: a pilot randomized controlled trial. Top. Stroke Rehabil., 23(1): 50-58.

6. Klimkiewicz P., Kubsik A., Woldańska-Okońska M. (2012) NDT-Bobath method used in the rehabilitation of patients with a history of ischemic stroke. Wiad. Lek., 65(2): 102-107.

7. Kazlauskas H.A., Raskauskiene N., Radziuviene R., Janusonis V. (2016) Twenty years trends in mortality rates from stroke in Klaipeda. Brain Behav., 6(8): e00499.

8. Kollen B.J., Lennon S., Lyons B., Wheatley-Smith L., Scheper M., Buurke J.H., Halfens J., Geurts A.C., Kwakkel G. (2009) The effectiveness of the Bobath concept in stroke rehabilitation: what is the evidence? Stroke, 40(4): e89-97.

9. Krukowska J., Bugajski M., Sienkiewicz M., Czernicki J. (2016) The influence of NDT-Bobath and PNF methods on the field support and total path length measure foot pressure (COP) in patients after stroke. Neurol. Neurochir. Pol., 50(6): 449-454. 
10. Langhammer B., Stanghelle J.K. (2011) Can physiotherapy after stroke based on the Bobath concept result in improved quality of movement compared to the motor relearning programme. Physiother. Res. Int., 16(2): 69-80.

11. Lee K.B., Lim S.H., Kim Y.D., Yang B.I., Kim K.H., Lee K.S., Kim E.J., Hwang B.Y. (2016) The contributions of balance to gait capacity and motor function in chronic stroke. J. Phys. Ther. Sci., 28(6): 1686-1690.

12. Mikołajewska E. (2015) NDT-Bobath method in poststroke rehabilitation in adults aged 42-55 years - preliminary findings. Pol. Ann. Med., 22(2): 98-105.

13. Mikołajewska E. (2013) Associations between results of post-stroke NDT-Bobath rehabilitation in gait parameters, ADL and hand functions. Adv. Clin. Exp. Med., 22(5): 731-738.

14. Mikołajewska E. (2013) Value of NDT-Bobath metod in post-stroke gait training. Adv. Clin. Exp. Med., 22(2): 261-272.

15. Mikołajewska E. (2012) Normalized gait parameters in NDT-Bobath post-stroke gait rehabilitation. Cent. Eur. J. Med., 7(2): 176-182.

16. Paci M. (2003) Physiotherapy based on the Bobath concept for adults with post-stroke hemiplegia: a review of effectiveness studies. J. Rehabil. Med., 35(1): 2-7.

17. Şimşek T.T., Çekok K. (2016) The effects of Nintendo Wii(TM)-based balance and upper extremity training on activities of daily living and quality of life in patients with sub-acute stroke: a randomized controlled study. Int. J. Neurosci., 126(12): 1061-1070.

18. Sohn M.K., Jee S.J., Hwang P., Jeon Y., Lee H. (2015) The effects of shoulder slings on balance in patients with hemiplegic stroke. Ann. Rehabil. Med., 39(6): 986-994.

19. Tang Q., Tan L., Li B., Huang X., Ouyang C., Zhan H., Pu Q., Wu L. (2014) Early sitting, standing, and walking in conjunction with contemporary Bobath approach for stroke patients with severe motor deficit. Top. Stroke Rehabil., 21(2): 120-127.

20. Taveggia G., Borboni A., Mulé C., Villafañe J.H., Negrini S. (2016) Conflicting results of robot-assisted versus usual gait training during postacute rehabilitation of stroke patients: a randomized clinical trial. Int. J. Rehabil. Res., 39(1): 29-35.

21. Vaughan-Graham J., Cott C., Wright F.V. (2015) The Bobath (NDT) concept in adult neurological rehabilitation: what is the state of the knowledge? A scoping review. Part II: intervention studies perspectives. Disabil. Rehabil., 37(21): 1909-1928.

\section{Received 28.12.2016 \\ Accepted 10.03.2017}

(C) University of Physical Education, Warsaw, Poland 